Article

\title{
Inclusive Higher Education Access for Underrepresented Groups: It Matters, But How Can Universities Measure It?
}

\author{
Anete Veidemane *, Frans Kaiser and Daniela Craciun \\ Center for Higher Education Policy Studies, University of Twente, The Netherlands; \\ E-Mails: a.veidemane@utwente.nl (A.V.), f.kaiser@utwente.nl (F.K.), d.craciun@utwente.nl (D.C.) \\ * Corresponding author
}

Submitted: 7 February 2021 | Accepted: 18 May 2021| Published: 21 July 2021

\begin{abstract}
Measuring access to higher education for underrepresented groups is a relevant yet challenging task. The article shows that while social inclusion is recognised as a priority, policymakers, academics, and institutional leaders struggle to define, operationalise, and measure it. This makes answering the question of what constitutes a socially inclusive higher education institution quite difficult. While the answer to this question may be context-specific, there is a clear need for a set of commonly defined indicators that allow higher education institutions to measure their progress throughout time and in relation to others. The article synthesises insights from policy, practise, and scientific research to identify which indicators are the most promising for assessing the access of under-representative students to higher education. By discussing indicator relevance, validity and feasibility, the article contributes to the quest for internationally comparable social inclusion indicators of underrepresented student groups.
\end{abstract}

\section{Keywords}

access; higher education; indicators; rankings; social inclusion; underrepresented students; university

\section{Issue}

This article is part of the issue "Inclusive Universities in a Globalized World" edited by Liudvika Leišyte (TU Dortmund, Germany), Rosemary Deem (Royal Holloway, UK) and Charikleia Tzanakou (Oxford Brookes University, UK).

(C) 2021 by the authors; licensee Cogitatio (Lisbon, Portugal). This article is licensed under a Creative Commons Attribution 4.0 International License (CC BY).

\section{Introduction}

\subsection{Problem Statement}

The inclusion of underrepresented groups in higher education is on supra-national and national policy agendas around the world (Claeys-Kulik et al., 2019). Governments are increasingly holding higher education institutions (HEIs) accountable for their performance in ensuring equity (Pitman et al., 2020). Measuring access to higher education for underrepresented groups is a relevant yet challenging task (Claeys-Kulik et al., 2019; Pitman et al., 2020). The central question that has yet to be answered is: access for whom? Clearly, the answer to this question is paramount for designing access indicators.
Research has shown that there are many different definitions and, as such, no unified understanding of what social inclusion means and who underrepresented groups or non-traditional students are (Chung et al., 2014; Kottmann et al., 2019). This makes answering the question of what constitutes a socially inclusive $\mathrm{HEI}$ a rather complex task. While the answer may be context-specific, there is a clear need for a set of commonly defined indicators that allow HEls to measure their progress throughout time and in relation to other institutions so they can monitor the effectiveness of their interventions and learn from good practices.

In this article, we continue the quest for such a set of indicators. We ask two central research questions: (1) What underrepresented groups are considered in describing social inclusiveness in access to higher 
education? (2) What are the most promising indicators for comparing the social inclusiveness of HEls in terms of access for underrepresented students?

To answer these questions, the article builds mostly on research done for the U-Multirank project, a multidimensional ranking and transparency tool that allows students, HEls and policymakers to compare the performance of HEls on a variety of issues (research, teaching \& learning, knowledge transfer, international orientation, regional engagement). U-Multirank aims to expand its coverage to new and highly relevant issues in higher education, such as social inclusion. For this purpose, exploratory analyses of policy documents and large-scale projects on social inclusion (e.g., rankings, international surveys) were conducted, and the identified indicators were discussed with a group of international experts and stakeholders to assess their relevance, validity, and feasibility for comparing the performance of HEls. In addition to expert and stakeholder insights on access indicators, we include preliminary findings from a broader ongoing systematic literature review on social inclusion in higher education.

\subsection{European Policy Context}

In the last decade, social inclusion in higher education has considerably advanced on the supra-national policy agenda in various forums such as the United Nations, the Bologna Process or the European Union. In 2015, the Sustainable Development Goals (SDGs) were adopted by the United Nations. Some of the key goals of this 17-point strategic agenda are ensuring gender equality (SDG 5), improving the quality of education (SDG 4) and reducing social inequality (SDG 10) by 2030 (United Nations, 2015). These SDGs seem to provide an answer to the central questions of inclusive access to higher education: access to whom, to what, and for what purpose?

Social inclusion is not a new policy priority in the higher education sector. In Europe, 'widening participation' has been high on the agenda for nearly three decades. However, a recent review on social inclusion policies in the EU found that definitions for underrepresented students vary across countries, and the lack of social inclusion indicators makes a meaningful comparison difficult (Kottmann et al., 2019). By looking at the heterogenous European context, we intend to highlight challenges and potential solutions relevant within and beyond Europe. We acknowledge that social inclusion policies have received considerable attention in the US (Goldrick-Rab et al., 2007), the UK (Gorard et al., 2019), and Australia (Pitman et al., 2020), yet policy reflections in these regions are beyond the scope of this section.

The Bologna Follow-Up Group (BFUG) on Social Dimension is one of the major steering bodies for social inclusion policies in the European Higher Education Area (EHEA). In 2015, it published the Widening Participation for Equity and Growth strategy, emphasising that in the 49 member states, "still too many capable students are excluded from higher education systems because of their socio-economic situation, educational background, insufficient systems of support and guidance and other obstacles" (Bologna Process, 2015, p. 1). Building on the 2015 strategy, in 2020, the BFUG proposed the Principles and Guidelines to Strengthen the Social Dimension of Higher Education (Bologna Process, 2020) adopted by the EHEA ministers. The new strategy proposes ten interconnected principles of accessibility, equity, diversity, and inclusion in higher education to be incorporated into member states' laws, policies, practices. Principle 4 explicitly states that "reliable data is a necessary precondition for an evidence/based improvement of the social dimension in higher education" and "higher education systems should define the purpose and goals of collecting certain types of data" (Bologna Process, 2020, p. 26). As before, the guidelines encourage member states to collect internationally comparable data and provide information on the composition of their student body within the limits of their national legal frameworks.

As part of the Europe 2020 strategy, the European Commission set the target of improving tertiary education attainment among the EU's population aged 30 to 34 from $31 \%$ in 2010 to $40 \%$ a decade later (European Commission, 2010). The EU target was reached in 2019, but there were discrepancies across member states (Eurostat, 2020). In 2017, the renewed EU agenda for higher education emphasised the importance of building inclusive and connected higher education systems that are open to talent from all backgrounds (European Commission, 2017). In 2018, the Council of the European Union issued recommendations on promoting common values, inclusive education, and the European dimension of teaching, inviting member states to provide the necessary support to all learners according to their needs and facilitate their transition across various educational levels and pathways (Council Recommendation of 22 May 2018,2018 ). The groups of learners identified included those from disadvantaged socioeconomic backgrounds, migrant backgrounds, and those with special needs.

What becomes apparent from the above-mentioned policies is a need to measure and compare the advancement of social inclusion throughout time and between countries and HEls. So, the question becomes: How can social inclusion in higher education be measured in an internationally comparable manner? Measurement theory distinguishes different levels and tasks for ensuring measurement validity: (1) Start from a background concept which includes the "broad constellation of meanings and understandings associated with a given concept" and through conceptualisation reach a systematised concept that has an "explicit definition" from which (2) indicators can be operationalised to (3) score empirical cases (Adcock \& Collier, 2001, p. 531). The insights gathered from this process should be used to refine indicators and fine-tune the systematised concept to ensure that our measurements are better capturing the phenomenon under scrutiny. The next sections 
will follow these steps providing an overview of insights from experts, academic literature and practice on how to measure social inclusion in higher education.

\section{Measuring Social Inclusion: Insights from Research and Practice}

To ensure that the article covers insights on measuring social inclusion in higher education from both research and practice, we conducted a review of both. First, we identified existing rankings and recent large-scale projects that fully or partially focus on social inclusion. These were the Times Higher Education Impact Ranking (THE Impact Ranking), the INVITED survey carried out by the European University Association (EUA; Claeys-Kulik et al., 2019) and the Australian Equity Ranking (Pitman et al., 2020). The list of projects is not exhaustive but offers current insights on relevant social inclusion measures used in practice.

Second, to ensure that the literature review presented in this article is representative of previously published scientific research on the access dimension of social inclusion in higher education, a systematic literature review methodology was employed. The literature synthesis on access presented here is part of a more extensive ongoing project that aims to provide an evidence gap map of review studies on social inclusion in higher education from the last two decades (2001-2020). The project followed the research design and methodological guidelines proposed by other systematic literature review studies in higher education research (Craciun \& Orosz, 2018; Grosemans et al., 2017). Literature was retrieved from four databases of scientific research (ERIC, Econlit, Scopus, Web of Science) using controlled keyword searches (see Table 1).

After removing duplicates, 39,720 unique references remained which were screened for relevance in Covidence-a systematic literature review management software. During the title and abstract screening, each publication was screened by two researchers and only those that met all three of the following inclusion criteria were kept: (1) focused on social inclusion issues at (2) the higher education level, (3) following a systematic literature review style research design. After the screening, 267 references moved to the full-text review, and we excluded items that met any of the following criteria: (1) They did not deal with access to higher education (i.e., for this article, we excluded articles that dealt with the other stages of social inclusion, see Figure 1), (2) had the wrong study design (did not follow systematic literature review methodological guidelines), (3) were not at higher education level, (4) were not written in English, (5) the full text was not available for review or (6) were not scientific publications (e.g., conference proceedings, reports, opinion pieces). A total of 26 articles passed the initial review and were categorised according to the theme covered. Four broad themes were distinguished: overviews of state of the art, barriers/enablers to participation, definitions/indicators, and the effectiveness of interventions to improve access. In line with the aim of the article, we only included insights from the systematic literature reviews which cover the theme of definitions/indicators (Chung et al., 2014; Gorard et al., 2019; Nikula, 2018; Spiegler \& Bednarek, 2013).

\subsection{Conceptualisation}

Shaped by changing norms and societal values, the meaning of social inclusion in higher education has shifted over time. Just a decade ago, social inclusion was seen as synonymous with higher education access (Gidley et al., 2010). The concept has evolved to include the whole educational career (i.e., steps prior, during, and after to higher education) $-a$ development visible in both scientific research (Gidley et al., 2010; Goldrick-Rab et al., 2007; Pitman et al., 2020; Salmi \& Bassett, 2014)

Table 1. Keywords used for database searches.

\begin{tabular}{lll}
\hline Literature type search term & Context search term & Topic search term \\
\hline Systematic literature review & Higher Education & Social inclusion \\
Meta-analysis & Post-secondary education & Access \\
Systematic review & Tertiary education & Outreach \\
Systematic synthesis & Student & Entry/Entr* \\
Evidence map & University & Social dimension \\
Evidence gap map & College & Participation \\
Qualitative review & & Equity \\
& & Diversity \\
& & Admission \\
& & Selection \\
& & Social integration \\
& & Participation \\
& & Success \\
\end{tabular}


and policy documents (Bologna Process, 2015, 2020). For example, the most recent principles and guidelines on social inclusion issued by the BFUG emphasise the need to move "beyond widening accessibility clauses and focusing on the concept of "leaving no one behind" " (Bologna Process, 2020, p. 24).

Gidley et al. (2010) note that access to higher education should be seen as the first step towards social inclusion, followed by participation and success, collectively representing 'degrees' of social inclusion. Salmi and Bassett (2014) and Pitman et al. (2020) also consider graduate outcomes (e.g., labour market outcomes, further study) as part of social inclusion and a report by the EUA (Claeys-Kulik et al., 2019) includes outreach activities prior to accessing higher education in the same process. Building on these ideas, social inclusion can be represented as a sequential process (see Figure 1) moving through different stages: from (1) outreach activities aiming to reduce the academic, aspirational, informational and personal barriers that restrict (2) access to higher education to underrepresented groups and impede (3) participation (or progress) in their studies towards (4) success (often marked by obtaining a degree) and further educational or labour market (5) outcomes.

To measure social inclusion at HEls across countries, we "need to proceed from a sound conceptual basis" (Pitman et al., 2020, p. 620). So how do we know social inclusion when we see it? We have identified the BFUG conceptualisation (Bologna Process, 2020) as a good standard since it is precise enough to incorporate a comprehensive understanding of the process and general enough to be applied to multiple contexts. Social inclusion in higher education entails that the "composition of the student body entering, participating in, and completing higher education at all levels should correspond to the heterogeneous social profile of society at large" and encompass "the creation of an inclusive environment in higher education that fosters equity and diversity and is responsive to the needs of local communities" (Bologna Process, 2020, p. 13). We adopt this as the substantive definition and background concept of social inclusion-a reference point for the article, recognising the consecutive steps of social inclusion (see Figure 1 ) and engagement with the community.

Due to the lack of consensus on internationally comparable social inclusion indicators (Kottmann et al., 2019) and to limit the scope of this article, we settle for a minimal definition as the systematised concept of social inclusion: access to higher education for underrepresented groups. As an early stage of social inclusion, 'access' is concerned with increasing the proportion of underrep- resented or disadvantaged students entering higher education but does not consider participation and success (Gidley et al., 2010). We are aware that access is not sufficient for achieving substantive social inclusion, but it covers the necessary condition. The need to restrict the concept to the minimal definition will immediately become apparent in the next sub-sections, where we discuss the difficulty in measuring social inclusion encountered by other large-scale projects (e.g., rankings, international surveys).

The article focuses on underrepresented groups as defined by the BFUG on Social Dimension. Underrepresented groups are those whose share among the students in relation to certain characteristics (e.g., gender, age, nationality, socioeconomic background, migratory background) is lower than the share of a comparable group in the total reference population. In addition to underrepresented students, BFUG also encourages collecting data on disadvantaged and vulnerable student groups. Disadvantaged students are those exposed to specific challenges compared to their peers in higher education, while vulnerable students are those at risk of disadvantage and have special (protection) needs. Vulnerable students need additional support and attention to prevent them from potential harm (Bologna Process, 2020). The status of both vulnerable and disadvantaged groups can be assigned temporarily, from time to time or prolonged periods, and may be removed if a certain obstacle (e.g., financial, physical, study restrictions) is addressed or eliminated. Students in these groups might self-identify as belonging to the group and needing a certain service (e.g., psychological counselling), or an institution might have predefined guidelines. With a few exceptions (e.g., physical disability), indicators on disadvantaged and vulnerable groups are less likely to utilise the total population as a reference group. Both groups may but do not necessarily overlap with underrepresented student groups. Due to these differences, we decided to focus on underrepresented student groups only.

For instance, a systematic literature review of 45 studies on 'non-traditional students' in higher education-an umbrella category similar to the label underrepresented students-found that there were "wide range variations on how the term was defined" (Chung et al., 2014, p. 1224). No less than thirteen different categories of meaning had been associated with the term in the studies reviewed. These were: age, sex, ethnicity, disability and trauma, having multiple roles in addition to being a student, mode of study (full-time vs part-time), having a gap in studies, having a commuter

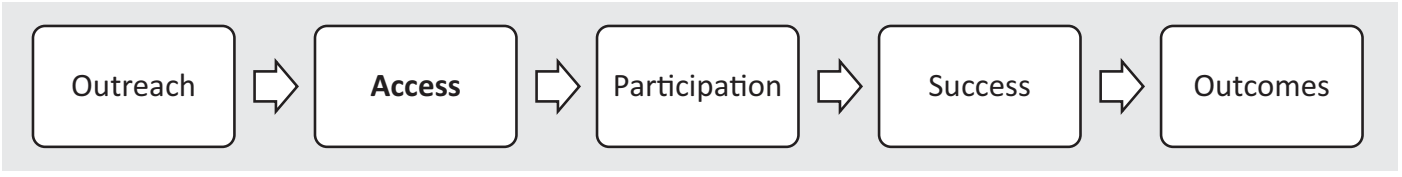

Figure 1. Constitutive stages of social inclusion in higher education. 
status (not living on campus), being demographically 'different' from the norm, admission pathway to higher education, enrolment in 'non-traditional' programs, being 'disadvantaged,' or having a previous degree. The article rightfully concludes that while it is essential to consider "societal, geographical and systemic context" in defining the terms, the "lack of consistency in categories in the definition of 'non-traditional students'... limits the usefulness of this already ambiguous term" (Chung et al., 2014, p. 1233).

Our conceptualisation of social inclusion also entails "the creation of an inclusive environment in higher education that fosters equity and diversity and is responsive to the needs of local communities" (Bologna Process, 2020, p. 13). To develop such an environment, institutions can pro-actively deploy a variety of intervention mechanisms such as outreach programs, non-discrimination policies, financial and housing support, flexible study path options. During the stakeholder consultations, we also discussed and collected information on the most promising access measures and interventions, yet these insights are beyond the scope of this article. Moreover, a recent article by Baltaru (2020) cautions against solely focusing on the display of inclusiveness measures without reference to the diversity of student and staff population, highlighting that elite HEls are more prone to present themselves as inclusive (e.g., through inclusiveness offices) without references to the diversity of student/staff population.

\subsection{Indicators}

Developing and selecting indicators to measure underrepresented student access to higher education is no easy task. While we might be able to reach a consensus in research, policy and practice on the broad dimensions of social inclusion, it "is far more difficult to quantify which indicators should be used to measure perfor- mance and even further, which indicators should be prioritised over others" (Pitman et al., 2020, p. 621). There is a need to balance validity criteria (i.e., providing an accurate picture of the phenomenon under study) with relevance criteria (i.e., the extent to which societal needs and priorities are addressed) and feasibility criteria (i.e., availability of data, cost of data collection, restrictions to data collection).

The INVITED survey (Claeys-Kulik et al., 2019) analysed responses from 159 HEls in 36 EHEA countries on their diversity, equity and inclusion strategies for students, academic and non-academic staff. The project surveyed various institutional types (e.g., comprehensive universities, universities of applied science, specialised universities, technical universities, open universities, music and/or art schools), but almost two-thirds of the sample was represented by comprehensive universities. The survey results showed that institutions collect data on a variety of underrepresented student groups (see Figure 2).

Overall, the two most often invoked rationales for collecting data on students were transparency, accountability and external reporting purposes (66\%) and to identify disadvantaged/less represented people (61\%). However, setting institutional strategic targets regarding social inclusion was not commonplace. The most frequent targets focused on gender (41\%), disability $(41 \%)$, socioeconomic background (24\%) and ethnic/cultural/migration background. Finally, two common indicators were used by HEls to measure the impact of social inclusion interventions: (1) number/share of students enrolled from less represented backgrounds (60\%) and graduation rate of students from underrepresented backgrounds (45\%; see Claeys-Kulik et al., 2019).

These results are encouraging in terms of the feasibility of collecting data on underrepresented groups in higher education. Nevertheless, they should be qualified. As the authors also noted, the survey was voluntary, and therefore self-selection bias is likely, i.e., only

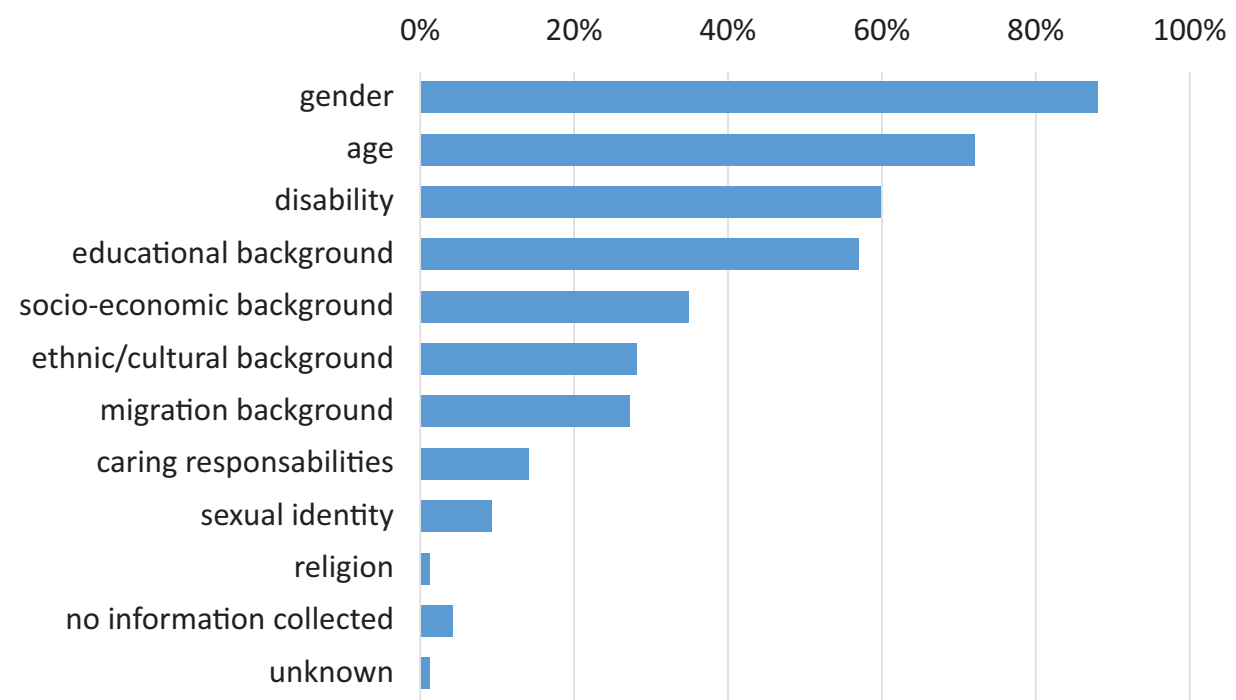

Figure 2. Percentage of responding HEls by type of underrepresented group for which information is collected ( $N=159)$. 
those institutions that collect data on underrepresented students responded, providing a skewed picture of the availability of such data at the institutional level. In addition, the results might also suffer from self-reported measures bias which "will generally be less reliable than information that has been administratively verified-due to misreporting, whether intentional or not" (Gorard et al., 2019 , p. 104). So, while the availability of data is essential, we should not use it as a sole criterion for selecting indicators. We should measure what we value rather than valuing what we can measure (Pitman et al., 2020). A systematic literature review of 231 research reports on indicators used in contextual admissions to higher education in England found that the indicators used in practice "are often chosen because they are readily available, without consideration of the quality of possible alternatives" (Gorard et al., 2019, p. 99). This is problematic for the validity of the results.

\subsection{Scoring Universities}

After we have selected and defined indicators, we can see how they work in practice by using them to score universities on these indicators. For instance, we could use them as rankings or benchmarking tools. The attempts to systematically score and rank HEls on the dimension of social inclusion are limited (Pitman et al., 2020). Our search for practical comparative large-scale examples has yielded two such efforts: (1) the THE Impact Ranking and (2) the Australian Equity Ranking. We will discuss both next.

First, the THE Impact Ranking was first released in 2019, and its latest edition from 2020 included $768 \mathrm{HEls}$ from 85 countries. It is currently the only ranking that assesses the performance of HEls against the UN SDGs. The goals relevant for this study are quality education for all (SDG 4), gender equality (SDG 5) and reduced inequalities (SDG 10; see Times Higher Education, 2020a). Each goal is measured through multiple weighted indicators: some measuring populations of underrepresented students and others measuring whether institutions have set up proactive interventions and policies to forward social inclusion. The underrepresented student indicators used to measure the performance of HEls in achieving the SDGs are the share of first-generation students in their first degree (SDG 4 and SDG 10), students and staff with disabilities (SDG 10), students from developing countries (SDG 10), first-generation female students (SDG 5), and women receiving degrees (SDG \%). The other indicators for the SDGs are either focused on relevant academic research (e.g., gender equality, lifelong learning), institutional policies and interventions (e.g., non-discrimination policies, maternity/paternity policies, childcare facilities, outreach) or student tracking (e.g., application, acceptance and completion race tracking; see Times Higher Education, 2020b, 2020c, 2020d).

The ranking provides its own definitions of categories, which may not be compatible with national/ institutional definitions and uses of the terms. For example, the THE first-generation student indicator is defined as "the number of students starting a first (bachelor's) degree who identify as being the first person in their immediate family to attend university, divided by the total number of students starting a first (bachelor's) degree" (Times Higher Education, 2020d). However, a systematic review of 70 research articles and reports on first-generation students finds that the indicator "does not necessarily mean to be the first student within the family as older siblings may have already attended university" (Spiegler \& Bednarek, 2013, p. 319). Even when the definition of first-generation students is solely related to parental education, the study finds that some definitions are broader than others. For instance, the US literature considers as first-generation students, not just those students whose parents have no higher education experience, but also those with some college education such as community college or associate degrees (Spiegler \& Bednarek, 2013). In fact, the authors find that there are such colossal divergences across countries in defining what it means to be a 'first-generation' student that there is limited comparability of cases across contexts.

Second, Pitman et al. (2020) ranked the 37 Australian public HEls on their equity performance on the access, retention, completion, and graduate outcomes of underrepresented students. The underrepresented groups identified and included in the ranking are students from a low socioeconomic background, indigenous students, students from regional and remote areas, students with a disability, and students from non-English speaking backgrounds. The ranking shows that underrepresented groups are considered as the most relevant category for measuring social inclusion in HEls. Nevertheless, the statement should be qualified by two important observations. On the one hand, the label 'underrepresented groups' is an umbrella term that covers different groups depending on the context. While both the Australian Equity Ranking and the INVITED survey (Claeys-Kulik et al., 2019) covered underrepresented groups, they contextually operationalised the term. Students from low socioeconomic backgrounds and with a disability were covered by both, but the INVITED survey did not collect data on most categories covered in Australia, such as indigenous students, students from regional and remote areas, and students from non-English speaking backgrounds. On the other hand, the indicators used in scoring cases might not provide an accurate picture of reality. After building an equity ranking of Australian HEls and analysing the results, the authors conclude that "out of the 33 potential indicators, only 5 were deemed appropriate for use" (Pitman et al., 2020, p. 621). For instance, the performance of an $\mathrm{HEI}$ in attracting underrepresented groups is not only determined by its interventions and policies to promote access but also by its location. Institutions in territories with larger populations of underrepresented groups tend to enrol a higher number of underrepresented students. Therefore, Pitman et al. 
(2020) propose the use of indicators sensitive to this reality to measure the impact of an institution's performance in relation to others. In addition to the access rate (the participation rate of underrepresented students in an $\mathrm{HEI}$ ), they suggest using an access ratio that adjusts the access rate to the relative population share of the relevant equity group in the institution's state or region.

As mentioned, the socioeconomic background is used as an indicator to gauge social inclusion both in Europe (e.g., INVITED survey) and Oceania (Australian Equity Ranking; see Pitman et al.,2020). However, a systematic review of 31 studies on socioeconomic inequalities in higher education in Finland and New Zealand found the use of socioeconomic status "problematic as it may be constructed from various data sources" (Nikula, 2018 , p. 2305). Reviewed studies operationalized socioeconomic status through parental education level $(n=14)$, parental occupation group $(n=11)$, socio-geographic area $(n=11)$, parental income level $(n=3)$, or other $(n=2)$. When it comes to comparable cross-country research, the study found that the various indicators are measured differently in the countries (e.g., considering characteristics of both parents or just the mother) or do not exist at all (i.e., socio-geographic area), which affects the comparability of institutions across contexts. Having reflected on the relevant literature and several largescale projects, we now move on to empirical insights obtained during stakeholder consultations and a broader discussion on the most promising indicators.

\section{Measuring Social Inclusion: Insights from Stakeholders and Further Discussion}

\subsection{Stakeholders Consulted}

Between September and December 2020, the U-Multirank project team conducted stakeholder consultations to identify the need for new social inclusion indicators. Among the stakeholders were the U-Multirank Advisory Board (16 participants), participants of three U-Multirank' benchmarking' workshops (49 participants), an expert panel on social inclusion (4 participants) and student representatives (7 participants). While the Advisory Board, 'benchmarking' workshop participants and students reflected on the relevance of social inclusion indicators more broadly, the expert panel provided insights on how to operationalise the specific underrepresented student groups. Despite student consultation being focused on indicator relevance, students provided several practical insights on indicator validity and feasibility. The U-Multirank Advisory Board consisted of representatives from intergovernmental organisations (e.g., OECD, IAU, EUA), student organisations (European Student Union [ESU], Erasmus Student Network [ESN]), university networks (EURASHE, CESAER) and institutional representatives of European HEls. The participants of the 'benchmarking' workshop were members of European university networks-ACUP,
ECIU and CEASAR. The four experts were representatives for the BFUG on Social Dimension at the EHEA, EUA INVITED project, UNESCO, and an expert on the US higher education system and inclusion efforts. Finally, the students represented ESU and ESN. The geographical coverage of the stakeholders was global (e.g., IAU, OECD, UNESCO), yet most of the stakeholders represented European institutions. No representatives were included from Asia, Australia, Africa, and Latin America. Thus, the insights presented here would be of most relevance to European countries and, to some extent, North America.

\subsection{Criteria for Indicator Assessment}

A broad initial list of indicators was considered for the stakeholder consultations and for inclusion in U-Multirank. Nevertheless, to ensure the consultations led to fruitful discussions on viable indicators, the list was narrowed following the insights gathered on measuring social inclusion in higher education from both research and practice. In line with the aim of U-Multirank and this article, indicators with the potential to be compared cross-nationally were pre-selected (see Table 2). For instance, indicators related to neighbourhood deprivation or types of schools attended, which are highly relevant, but for which data is not widely available outside the UK context, were excluded. Stakeholders were invited to reflect on three criteria for indicator assessment: relevance, validity, and feasibility. All three criteria are commonly used in the research literature on education indicators (Cave, 1997; Kaiser, 2003; Nuttal, 1994). The relevance criterion was considered paramount since "all efforts to develop an indicator are in vain if the indicator is not used" (Kaiser, 2003). To assess the relevance of various underrepresented student groups, we explored the importance of these groups in recent policy documents, large scale projects and academic literature and validated these insights during stakeholder consultations. Identifying which categories are important to stakeholders and institutional leaders was essential since institutions would not invest time in collecting data on measures of limited interest. The next criteriavalidity-refers to whether an indicator describes the phenomenon it is believed to be associated with (Bottani \& Tuijnman, 1994, p. 31). Since our adopted definition of social inclusion aims to attain a student population that represents the heterogeneous profile of society at large, focus on underrepresented students was deemed reasonable, but possible operationalisations of various sub-groups needed to be further explored. Finally, feasibility refers to practical aspects of data collection such as institutions' ability and willingness to collect the required data, given capacity, cost, expertise (Nuttal, 1994) and, in some cases, legal constraints (Claeys-Kulik et al., 2019). The following sections reflect on stakeholder feedback regarding the three criteria-relevance, validity, feasibility. It also discusses how stakeholder feedback relates to previously examined literature. 
Table 2. Overview of underrepresented student groups and considerations for operationalisation, consolidated insights.

\section{Underrepresented}

group Considerations for the operationalisation of the indicators

New entrants from low socioeconomic background

First-generation students

Students with

disabilities

Migrant or

indigenous students may not always disclose it.
The indicator is frequently used in literature and practice and considered highly relevant by experts and stakeholders. However, the socioeconomic background may be operationalised in multiple ways-a threat to the validity in an international comparative setting. Although definitions are not always fully aligned, information on the socioeconomic background is often collected by national statistical agencies, possibly fostering common definitions. Since the composition of the population by socioeconomic background may differ between regions, the regional population's use would create a more valid result (Pitman et al., 2020) than the national population or the composition of the institutional student body.

In UN SDGs, in the literature and in a current data project (THE Impact ranking), this indicator has a prominent place and is therefore seen as highly relevant. Definitions for first-generation students differ, with some definitions being more restrictive than others (e.g., none of the parents had tertiary education, only one parent had tertiary education, none of the siblings and parents has tertiary education). Here again, the choice of reference group when operationalising the indicator may be important as there are regional differences in the higher education attainment of the population.

Students with disabilities are a relatively well-recognised group in policy priorities and research and is a group that is relevant and generalisable to most contexts worldwide. A disability may refer to diverse types of impairment, and definitions are not always clear on selection criteria. Moreover, research suggests that due to stigma associated with disability, students may choose to not disclose their disability and others are misdiagnosed, which reduces the validity (Lombardi et al., 2018). The feasibility of this indicator is still considered to be medium as research has shown that institutions are likely to collect the data, but students

The relevance of this indicator is rising as many institutions host students with a migrant background due to increasing internationalisation and mobility for work and studies. An indicator of indigenous students is relevant in some regions (not in Europe). At the international level, no universally accepted definition for migrant exists, which may have an impact on the validity of the indicator. Since the composition of the population regarding migrant or indigenous status may differ by region, region-based reference groups should be considered.
Potential indicator

The number of new entrants with a low social economic background as a percentage of the total number of new entrants, normalised by the regional percentage of population with low socio-economic background.

The number of new entrants who are the first student in his/her immediate family, as a percentage of the total number of new entrants, normalised by the regional level of higher education attainment.

The number of new entrants with disabilities as a percentage of total number of new entrants. Disabilities refer to health, sight, hearing and speech impairments, and learning disabilities.

The number of new entrants with migrant background as a percentage of total number of students, normalised by the regional percentage of population with migrant background. 
Table 2. (Cont.) Overview of underrepresented student groups and considerations for operationalisation, consolidated insights.

\section{Underrepresented}

group

Ethnic minorities

Mature students

Gender balance*

$$
\text { Considerations for the operationalisation of the indicators }
$$

There is a general agreement that such a characteristic as ethnicity should not be an obstacle to higher
education access and has long been one of the priorities in policy documents. Data on ethnicity can be sensitive and even restricted by law in some countries. Definitions often depend on historical developments in national contexts, and internationally comparable definitions may not be readily available. Data based on national definitions may be retrieved from statistical agencies.

In all knowledge economies, lifelong learning and participation of mature students in higher education are high on policy agendas. The EHEA has a goal to have 50\% of Europeans engaged in lifelong learning by 2025. International organisations define mature students in similar ways, which makes international comparability and feasibility high.

This indicator is on global (UN SDGs) and European (EHEA) agendas, often with a focus on the field level, especially in STEM fields. However, recent debates have questioned whether dichotomous categories are sufficient to capture gender. Definitions used for this indicator are similar across countries and institutions. In most cases, data are readily available.

\section{Potential indicator}

The number of new entrants with ethnic minority background as a percentage of total number of students, normalised by the regional percentage of population with ethnic minority background.

The number of new entrants older than 29 years as a percentage of total number of new entrants.

The number of ( $\mathrm{fe}$ )male new entrants as a percentage of the total number of new entrants.

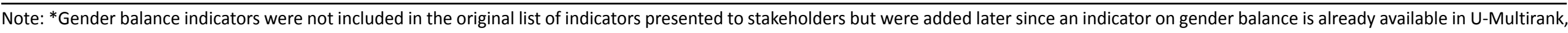
and hence was not proposed as a 'new' indicator. 


\subsection{Relevance}

The Advisory Board members, the U-Multirank workshop participants and student representatives considered social inclusion indicators to be of high importance and advised to include such indicators in following U-Multirank editions. Reflecting on the new indicators, student representatives saw first-generation students and students from a low-socio-economic background as high priority underrepresented groups but also emphasised that disability needs to be addressed along with accompanying measures.

The expert panel ( 4 members) provided more indepth feedback on indicator operationalisation. Having reviewed the preliminary list of underrepresented student categories (see Figure 1), experts agreed that all six categories are relevant but did not identify priority groups. The list contained the following student categories: low socioeconomic background, first-generation, disability, migrant or indigenous, ethnic minority and mature students. In addition, the expert panel proposed several other groups for consideration: refugee students \& students seeking asylum, gender balance in certain study fields (e.g., STEM), students from rural areas, homeless students, students with children, students from alternative pathways (e.g., vocational education). While experts thought that acknowledging other underrepresented groups is important, it was also agreed that the number of groups should not be too large and context-specific, particularly in a ranking tool, where comparability is paramount. Thus, it was agreed that using the six groups should be sufficient. Gender balance was not included in the preliminary list of new indicators because U-Multirank already has indicators on gender balance, but it was shown to stakeholders as an example of a relevant existing social inclusion indicator, given the importance of gender indicators in European policy discourse (European Commission, 2020; Leišytè, 2019).

At the institutional level, the number of groups might be customised to fit the context-specific needs. The input received from stakeholders aligned with the general trends found in higher education policy documentssocial inclusion is an increasingly relevant topic in the higher education sector (European Commission, 2017, 2020), and there is a growing interest to capture social inclusion indicators in a systematic and transparent manner (Bologna Process, 2020).

\subsection{Validity}

The expert panel considered the underrepresented student categories (Table 2) to be valid for identifying underrepresented students accessing higher education. The key concern was the international comparison of various underrepresented groups, which would have different definitions and qualifying criteria across countries and regions. For example, definitions for groups such as first-generation students, low-income (or low SES) or migrant students might use either more or less restrictive definitions (e.g., first-generation students), different thresholds (e.g., a limit for low-income students) or criteria (income data, zip-codes, educational attainment of parents for low socioeconomic background). A recent study on social inclusion measures in Europe indicates that data on underrepresented groups and social inclusion measures more broadly are not collected in a comprehensive and systematic manner (Kottmann et al., 2019). Thus, agreeing on transparent and crossnationally applicable definitions would be necessary. Moreover, the use of different definitions or criteria would have a considerable impact on the final scores and international comparability, even if the indicator is valid at the institutional level for their intended purposes. Experts also noted that when data collection is legally restricted in some countries, contextual information should be provided to explain the deviances in the scores.

Student representatives noted that amongst existing U-Multirank indicators, gender is expressed as a binary category and recommended to expand the options if possible. It was flagged as an issue because not every student identifies with the binary categories, yet most are classified and addressed within these categories at HEls.

\subsection{Feasibility}

The expert panel as well as students reiterated that data collection for underrepresented groups might be restricted by several factors, including legal constraints in some countries, as also shown by the INVITED survey (Claeys-Kulik et al., 2019). In addition, experts proposed not to develop too many categories for underrepresented groups since it may lead to having too few students in each group and overburdening HEls with data provision. Furthermore, clear and cross-nationally applicable definitions are necessary to ease the data collection process. Nevertheless, it is anticipated that the new principles and guidelines proposed by the BFUG on Social Dimension will facilitate a more coordinated approach across European HEls, focusing on underrepresented, disadvantaged, and vulnerable groups (Bologna Process, 2020).

\subsection{Prioritising Indicators}

All four stakeholder groups considered the six underrepresented student groups as highly relevant. While additional groups were identified, experts advised keeping the list short to ease data collection process and international comparison. Given the international relevance of the six groups, practical considerations (feasibility) such as availability of data and legal restrictions will likely determine the priority groups. In cases when data is available for all groups, but institutions need to prioritise some groups over others, institutions should reflect on the purpose for collecting the data. If the intention is to 
consequently reduce the barriers for these groups, institutions may want to prioritise those groups where barriers can be reduced. Moreover, it is worth investigating which groups overlap or entail several other groups in the specific national or institutional context and prioritise these groups (e.g., first-generation students may entail students from the low-socioeconomic background, migrant or indigenous students and ethnic minorities). Yet, such an approach may exclude relevant sub-groups and key information. Therefore, the authors recommend exploring all six groups while considering local context and institutional priorities.

\section{Conclusion}

This article examined how underrepresented groups can be operationalised in practice, learning from a project carried out by U-Multirank on identifying indicators for underrepresented students and preliminary insights from a systematic literature work. Having looked at academic literature (Chung et al., 2014; Gorard et al., 2019; Nikula, 2018; Spiegler \& Bednarek, 2013), policy documents (focus on Europe; see Bologna Process, 2020; Council Recommendation of 22 May 2018, 2018; European Commission, 2017; United Nations, 2015) and large-scale projects (Claeys-Kulik et al., 2019; Pitman et al., 2020; Times Higher Education, 2020a), we presented a list of indicators for underrepresented student groups, discussed their operationalisation and limitations. The study might be of value to academics interested in social inclusion as well as institutional practitioners seeking to develop internationally comparable indicators on underrepresented groups at their institutions.

\subsection{Recommendations to Institutional Leaders}

To support institutional leaders in developing relevant, valid, feasible, and internationally comparable indicators, we have proposed a few recommendations. First, institutional leaders should identify underrepresented student groups (most) relevant to their context. In this article, we have identified seven underrepresented student groups that are likely to be applicable to a wide spectrum of countries/institutions while acknowledging that numerous other groups exist that may be more context-specific (e.g., indigenous students) as shown by Pitman et al. (2020). This highlights a dilemma between regional relevance and international comparability, and both are important considerations. The selection of the groups may depend on numerous factors, including historical context, geographical location, disciplinary focus, legal regulations, and national and international policy discourse.

Next, the literature has shown that a wide spectrum of definitions and criteria exist for identifying underrepresented or non-traditional student groups (Chung et al., 2014). While the definition and underlying crite- ria should primarily aim to capture the phenomenon of interest (validity), it is also important to remain transparent and consider the international comparability of indicators. This may also reduce workload in the future if data needs to be reported either at the national or international level. Moreover, not only the criteria for underrepresented groups are important, but also the reference groups used. Some institutions choose to use the total student population as a reference group, while a more representative manner would be to include the regional or national representation as a reference group, also suggested by the definition offered by the BFUG on Social Dimension (Bologna Process, 2020). This, however, requires access to and dependence upon external data.

Furthermore, a clear trade-off exists between the relevance and feasibility of data collection. If the number of relevant student groups becomes too large and granular, the cost associated with collecting and processing data as well as communicating results increase. Finally, as highlighted in this article, social inclusion is gaining momentum on the higher education policy agenda, and initiatives to collect comparable data at the European level and beyond are underway (Bologna Process, 2020; Claeys-Kulik et al., 2019; Pitman et al., 2020; Times Higher Education, 2020a). Investing early in social inclusion efforts at the institutional level is likely to be worthwhile in the long run. Ensuring clear definitions and transparency of indicators are essential for making indicators nationally and internationally comparable.

\subsection{Limitations and Avenues for Further Research}

This study offers insights on how to conceptualise and operationalise social inclusion indicators for underrepresented groups in an international context, yet it has its limitations. First, the scope of the article was restricted to underrepresented groups entering higher education. Hence, it did not reflect on the indicators in the further stages of higher education (e.g., participation, outcomes). Moreover, by focusing solely on underrepresented student groups, it did not consider other classifications such as vulnerable and disadvantaged groups as proposed by the latest Principles and Guidelines of the BFUG on Social Dimension (Bologna Process, 2020). Furthermore, the scope of policy analysis as well as expert consultations were primarily focused on the European higher education sector and may not be generalisable to other geographical areas. Lastly, this article did not address the intersectionality of underrepresented student groups (Claeys-Kulik et al., 2019). While these themes were beyond the scope of this article, the topics deserve further attention in the research community.

Specifically, we see fruitful avenues of further research on social inclusion in higher education in three areas. First, an up-to-date survey and comparison of universities to find out what data they already collect or intend to collect in the near future that could be useful in measuring social inclusion is needed (e.g., age, gender, 
disability, ethnicity, first-generation students, low socioeconomic status). Coupled with an overview of the legal restrictions for data collection in different national contexts, this like of research would get us closer to a list of viable cross-nationally comparable indicators. Second, ethical research on underrepresented, disadvantaged, and vulnerable groups is needed to better understand their composition, the barriers they face, and what interventions work in promoting their inclusion in higher education. Little progress will be made on the social dimension of the Bologna Process without such insights. Third, there is already a plethora of research on all stages of social inclusion in higher education, not just access. A systematic literature review of the last decades of research in this area could help to understand not just what the actual research gaps are or how to measure social inclusion in higher education, but what works. We encourage researchers to explore these themes and reflect on how the insights presented in this article may be applicable to other contexts beyond Europe.

\section{Acknowledgments}

We thank higher education experts, practitioners, and student representatives for their active participation and rich insights provided during stakeholder consultation on new social inclusion indicators.

\section{Conflict of Interests}

The authors declare no conflict of interests.

\section{References}

Adcock, R., \& Collier, D. (2001). Measurement validity: A shared standard for qualitative and quantitative research. The American Political Science Review, 95(3), 524-546.

Baltaru, R. D. (2020). The rise of agentic inclusion in the UK universities: Maintaining reputation through (formal) diversification. Studies in Higher Education. https://doi.org/10.1080/03075079.2020.1739015

Bologna Process. (2015). Widening participation for equity and growth. A strategy for the development of the social dimension and lifelong learning in the European higher education area to 2020. EHEA. http://www.ehea.info/media.ehea.info/file/2015_ Yerevan/71/5/Widening_Participation_for_Equity_ and_Growth_A_Strategy_for_the_Development_ of_the_SD_and_LLL_in_the_EHEA_to_2020_ 613715.pdf

Bologna Process. (2020). Advisory group 1 on social dimension final report. Italian BFUG Secretariat. https://ehea2020rome.it/storage/uploads/ 0479534b-a889-4fd9-9d15-64b49e6ee768/ AG1_Social_Dimension_Final_Report.pdf

Bottani, N., \& Tuijnman, A. (1994). International education indicators: Framework, development and inter- pretation. Capítulo, 1, 21-35.

Cave, M. (1997). The use of performance indicators in higher education: The challenge of the quality movement. Jessica Kingsley Publishers.

Chung, E., Turnbull, D., \& Chur-Hansen, A. (2014). Who are 'non-traditional students'? A systematic review of published definitions in research on mental health of tertiary students. Educational Research and Reviews, 9(23), 1224-1238.

Claeys-Kulik, A.-L., Jørgensen, T. E., \& Stöber, H. (2019). Diversity, equity and inclusion in european higher education institutions: Results from the INVITED project. European University Association. https:// eua.eu/downloads/publications/web_diversity\% 20equity\%20and\%20inclusion\%20in\%20european\% 20higher\%20education\%20institutions.pdf

Council Recommendation No. 2018/C 195/01 of 22 May 2018 on promoting common values, inclusive education, and the European dimension of teaching. (2018). Official Journal of European Union, C 195/1. https://eur-lex.europa.eu/legal-content/EN/TXT/

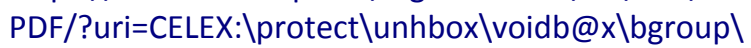
def, $\{32018$ H0607\}\let \futurelet\@let@token\ let\protect\relax\itshape32018H0607\egroup(01) \&from $=\mathrm{EN}$

Craciun, D., \& Orosz, K. (2018). Benefits and costs of transnational collaborative partnerships in higher education (EENEE Analytical Report No. 36). European Expert Network on Economics of Education. http://www.eenee.de/eeneeHome/EENEE/ Analytical-Reports.html

European Commission. (2010). Communication from the Commission Europe 2020: A strategy for smart, sustainable and inclusive growth. European Commission. https://ec-europa-eu.ezproxy2.utwente.nl/ eu2020/pdf/COMPLET\%20EN\%20BARROSO\%20\%20 \%20007\%20-\%20Europe\%202020\%20-\%20EN\%20 version.pdf

European Commission. (2017). Communication from the Commission to the European Parliament, the Council, the European economic and social committee and the committee of the regions on a renewed EU agenda for higher education. European Commission. https://eur-lex.europa.eu/legal-content/EN/ALL/ ?uri=CELEX:52017DC0247

European Commission. (2020). Communication from the Commission to the European Parliament, the Council, the European economic and social committee and the committee of the regions on achieving the European education area by 2025. European Commission. https://ec-europa-eu/education/sites/default/ files/document-library-docs/eea-communicationsept2020_en.pdf

Eurostat. (2020). Educational attainment statistics: Statistics explained. Eurostat. https://ec-europa-eu. ezproxy2.utwente.nl/eurostat/statistics-explained/ pdfscache/32198.pdf

Gidley, J. M., Hampson, G. P., Wheeler, L., \& Bereded- 
Samuel, E. (2010). From access to success: An integrated approach to quality higher education informed by social inclusion theory and practice. Higher Education Policy, 23(1), 123-147.

Goldrick-Rab, S., Carter, D. F., \& Wagner, R. W. (2007). What higher education has to say about the transition to college. Teachers College Record, 109(10), 2444-2481.

Gorard, S., Boliver, V., Siddiqui, N., \& Banerjee, P. (2019). Which are the most suitable contextual indicators for use in widening participation to HE? Research Papers in Education, 34(1), 99-129.

Grosemans, I., Coertjens, L., \& Kyndt, E. (2017). Exploring learning and fit in the transition from higher education to the labour market: A systematic review. Educational Research Review, 21, 67-84.

Kaiser, F. (2003). System-level indicators for higher/ tertiary education: Some notes on requirements and use. In A. Yonezawa \& F. Kaiser (Eds.), System-level and strategic indicators for monitoring higher education in the twenty-first century (pp. 31-35). UNESCOCEPES.

Kottmann, A., Vossensteyn, J., Kolster, R., Veidemane, A., Blasko, Z., Biagi, F., \& Sánchez-Barrioluengo, M. (2019). Social inclusion policies in higher education: Evidence from the EU. European Commission.

Leišytè, L. (2019). Gender in European research policy. In D. Simon, S. KuhImann, J. Stamm, \& W. Canzler (Eds.), Handbook on science and public policy (pp. 284-315). Edward Elgar Publishing

Lombardi, A., Gelbar, N., Dukes, L. L., III, Kowitt, J., Wei, Y., Madaus, J., Lalor, A. R., \& Faggella-Luby, M. (2018). Higher education and disability: A systematic review of assessment instruments designed for students, faculty, and staff. Journal of Diversity in Higher Education, 11(1), 34-50.

Nikula, P. (2018). Socio-economic inequalities in higher education: A meta-method analysis of twenty-first century studies in Finland and New Zealand. Studies in Higher Education, 43(12), 2305-2320.

Nuttal, D. (1994). Choosing indicators. In A. Tuijnman \& N.
Bottani (Eds.), Making education count: Developing and using international indicators (pp. 79-94). Centre for Educational Research and Innovation.

Pitman, T., Edwards, D., Zhang, L. C., Koshy, P., \& McMillan, J. (2020). Constructing a ranking of higher education institutions based on equity: Is it possible or desirable? Higher Education, 80(4), 605-624.

Salmi, J., \& Bassett, R. M. (2014). The equity imperative in tertiary education: Promoting fairness and efficiency. International Review of Education, 60(3), 361-377.

Spiegler, T., \& Bednarek, A. (2013). First-generation students: What we ask, what we know and what it means: an international review of the state of research. International Studies in Sociology of Education, 23(4), 318-337.

Times Higher Education. (2020a). Impact ranking 2020. Times Higher Education. https://www. timeshighereducation.com/rankings/impact/2020/ overall\#!/page/0/length/25/sort_by/rank/sort_ order/asc/cols/undefined

Times Higher Education. (2020b, April 17). THE impact rankings 2020 by SDG: gender equality (SDG 5) methodology. Times Higher Education. https://www. timeshighereducation.com/impact-rankings-2020sdg-gender-equality-sdg-5-methodology

Times Higher Education. (2020c, April 17). THE impact rankings 2020 by SDG: quality education (SDG 4) methodology. Times Higher Education. https://www. timeshighereducation.com/impact-rankings-2020sdg-quality-education-sdg-4-methodology

Times Higher Education. (2020d, April 17). THE impact rankings 2020 by SDG: reduced inequalities (SDG 10) methodology. Times Higher Education. https:// www.timeshighereducation.com/impact-rankings2020-sdg-reduced-inequalities-sdg-10-methodology

United Nations. (2015). Transforming our world: The 2030 agenda for sustainable development (A/RES/70/1). Sustainable Development UN. https:// sustainabledevelopment.un.org/content/ documents/21252030\%20Agenda\%20for\%20 Sustainable\%20Development\%20web.pdf

\section{About the Authors}
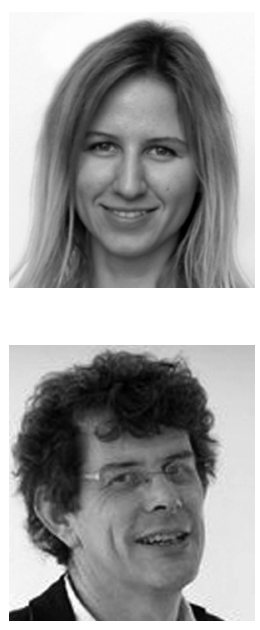

Anete Veidemane (MSc), a graduate of Master of Research and Innovation in Higher Education, works as a Researcher at the Center for Higher Education Policy Studies (CHEPS) in the Netherlands since 2018. Her work entails projects centered around embedding sustainability in academic departments (e.g., DECODE project), developing new indicators on social inclusion and education for sustainable development (U-Multirank project), and piloting a European framework for community engagement (TEFCE project) as well as a European-wide comparative policy research. Before joining CHEPS, Anete interned at the UN and OECD.

Frans Kaiser holds a master's in public administration. He works at the Center for Higher Education Policy Studies at the University of Twente, the Netherlands, since 1988. During his career at CHEPS he has been involved in numerous international comparative studies on higher education policies and trends in higher education. He coordinated a number of projects in which tools and visualizations were developed to allow analyses and presentations of large and complex datasets on higher education and higher education institutions. The U-Map project (2007-2018) and the U-Multirank project (2009-present) are major examples of the latter. 


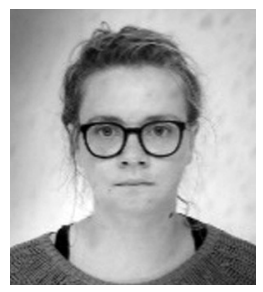

Daniela Craciun is a Researcher at the Center for Higher Education Policy Studies (CHEPS), University of Twente. She is an inter-disciplinary researcher with experience in the field of higher education policy, particularly internationalization, employability and social inclusion. Daniela earned a PhD in Public Policy at Central European University and has co-authored consultancy reports on higher education for the European Commission and the World Bank. 